\title{
Technical Barriers, Import Licenses and Tariffs as Means of Limiting Market Access
}

\author{
Jan G. Jørgensen \\ University of Southern Denmark \\ Philipp J.H. Schröder \\ Aarhus School of Business
}

\begin{abstract}
Technical barriers (standards), import licenses and tariffs may be deployed as means of limiting the market access of foreign firms. The present paper examines these measures in a setting of monopolistic competition. We find that, if protection focuses predominantly on the number of foreign firms accessing the domestic market, a technical barrier (an import license) may dominate a tariff (tariff and a technical barrier) in terms of consumer welfare, even when tariff revenues are fully redistributed. However, if protection pays sucfficient focus on limiting the total import volume, then tariffs are the preferred means of protection. Within the model, reductions in technical barriers and tariffs, the removal of licensing schemes, and a harmonization of standards are all welfare-improving policies.
\end{abstract}

- JEL classifications: F12, F15

- Key words: non-tariff barriers, technical trade barriers, standards, import licenses, monopolistic competition

\footnotetext{
*Corresponding address: Jan Guldager Jørgensen University of Southern Denmark, Department of Business and Economics, Campusvej 55, DK-5230 Odense M, Denmark, Tel: +45-6550-2151, Fax: +45-6615-8790, E-mail: jgj@sam.sdu.dk.

Philipp J. H. Schröder, Aarhus School of Business, Department of Economics, Fuglesangs Allé 4, DK8210 Aarhus V, Denmark, Tel: +45-8948-6392, Fax: +45-8948-6197, E-mail: psc@asb.dk and DIW Berlin.

@2006-Center for International Economics, Sejong Institution, All Rights Reserved.
} 


\section{Introduction}

With the far-reaching progress of global trade liberalization, interest groups in industry and governments alike have relied on non-tariff trade barriers to protect their markets from foreign competition, see e.g. Baldwin (1984), Bhagwati (1988), Maskus and Wilson (2001). Technical barriers or standards in particular are often abused as protective measures, for example to discourage foreign firms from accessing the domestic market. With the continuing liberalization of visible trade barriers such as tariffs and quotas, the importance of technical regulations as means of restricting trade and limiting market entry has gained in importance. ${ }^{1}$ A study by the US Department of Agriculture by Roberts and DeRemer (1997) finds that in 1996, 57 European regulations affected US exports in agriculture corresponding to an estimated trade impact of 899.55 million dollars. Weyerbrock and Xia (2000) identify further EU/US technical regulations impeding bilateral trade. The EU Commission has calculated that in 1996, over 79 per cent of intra-EU trade is potentially affected by standards (EU-Commission, 1998). According to Brenton et al. (2001), the success of an EU enlargement with up to 10 new member states in terms of trade depends crucially on the full access of those countries to the internal market of the EU, and hence on the removal of technical barriers to trade. However, technical regulation differs across sectors and hence, due to differences in industry specialization the impact and importance of technical barriers vary across the countries set to become new members of the EU (Brenton and Manzocchi (2002)). Alternative means of controlling market access are, of course, tariffs or import licenses, whereby the latter tool is the most direct means of controlling the entry of foreign firms. The purpose of this paper is to examine the impact of these different means of restricting market access on firm entry decisions, firm size and welfare. The paper is not concerned with the rationale for such protectionist policies, but with their economic impact and the expected welfare effect from replacing the one type of policy with another.

Overall, our results show that in a world of monopolistic competition featuring intra industry trade, the different means of limiting market access are nonequivalent in terms of the welfare consequences that arise. Reducing the market access of foreign firms servicing the domestic market below the free trade equilibrium always reduces total consumer welfare. If the protective measure

${ }^{1}$ See Maskus and Wilson (2001) for a survey on both theoretical and empirical approaches to technical barriers and trade. 
solely focuses on limiting the number of foreign firms active on the domestic markets, the following welfare rankings of policy tools apply. In terms of converting a certain existing technical barrier to trade, then, for moderate levels of protection, replacing the technical barrier by a tariff or an import license - while still permitting the same number of foreign firms - increases welfare, whereby the import license generates the highest welfare. However, for high levels of protection - i.e. a severe restriction on the number of foreign firms - replacing the technical barrier by a tariff in fact reduces welfare, while the creation of a licensing scheme still improves welfare. If the protective measure takes sufficient account of the total import volume these rankings change. Now the tariff is the dominant tool. Furthermore, if a certain level of protection is aimed at the import license may not only be dominated by the tariff but also by a technical barrier. These welfare rankings carry potentially important insights for the efforts of the Uruguay round trade liberalization to replace technical barriers to trade. Finally, our results also show that the harmonization of standards (reducing technical barriers) will improve welfare unambiguously. ${ }^{2}$

The paper develops a simple, symmetric, two-country trade model based on Krugman (1980 and 1981) and using extensions by Venables (1994). Technical barriers to trade or standards are modelled as an increase in fixed cost without any direct welfare implications stemming from the technical barrier or standard as such, i.e. the barrier is only viewed as a means of controlling market access without any real implications for product quality, etc. Hence, it is viewed as a pure cost increase as in, e.g., Ganslandt and Markusen (2001) and Brenton, et al. (2001). The license, on the other hand, is modelled as an import permit sold by the government to foreign producers, with a price set to limit access of foreign firms to the domestic market, whereby all license revenues are redistributed to consumers. ${ }^{3}$ Finally, following Gros (1987), an ad valorem tariff is introduced into the model, again reducing the market access of foreign firms while redistributing all revenues to

\footnotetext{
${ }^{2}$ Casella (1997) has another focus: she analyzes how product standards are influenced by private coalitions of firms in open economies. Ker's (2000) focus is on modelling technical barriers and uncertainty where the uncertainty arises from the variation in product attributes. Chen (2004) shows by using a gravity equation that technical barriers to trade increase the national border effects among European countries.

${ }^{3}$ In the present paper, the allocation of licenses (e.g. through auctions or historical allocation) and price determination are of no concern. The different methods of allocating import licenses applied by the WTO under the tariff-rate-quota system are surveyed in Skully (1999). Gervais and Surprenant (2000) formally study the impact of the different WTO import license allocation mechanisms on welfare. Import licenses auctions under imperfect competition are studied in detail by Krishna (1993).
} 
consumers. From these three measures, we derive welfare rankings under identical levels of protection. We distinguish two cases of market access limitation (protection). Firstly, we examine a special case where protection only focuses on firm entry, i.e. the number of foreign firms that penetrate the domestic market. Secondly, we examine a more general case where the restriction of market access focuses on an measure of protection composed from both the number of foreign firms and total foreign imports. The following results are obtained: in the simple case, where only the number of foreign firms are of concern we find that for low levels of protection, the tariff is welfare superior to a technical barrier, but for high levels of protection the technical barrier generates the higher welfare. An import license dominates both these arrangements for all levels of protection. For the more general measure of protection, i.e. once total import volumes enter as an objective, the tariff becomes quickly the dominant tool. Technical barriers, though commanding less welfare than the tariff and the license for low levels of protection, may dominate a licensing scheme for high levels of protection.

What drives these welfare rankings of the three measures is the nature of the cost imposed upon the foreign producer. While technical barriers or standards tie up resources, e.g. firms have to hire people to deal with administrative red tape or face additional costs from implementing foreign regulation and safety requirements before their goods can access the foreign market, a license simply imposes a fixed cost, still reducing entry but absorbing no actual resources. Rather, the license fee is reallocated from the foreign producer to the domestic government and eventually consumers. Similarly, a tariff does limit the number of importing firms by distorting their cost structure, yet reallocates all revenues. The important difference between the three tools, and the reason why the tariff performs badly under the simple measure of protection but dominates the other tools for the more complex measure of protection, is that although all the different measures limit the number of foreign firms, only the tariff succeeds in actually reducing the trade volume, since foreign firms react to it by increasing prices, resulting in lower sales. On the other hand, under a technical barrier or import license, those foreign firms that decide to enter the domestic market will in fact increase their export volume so as to be able to recover the increase in fixed costs caused by the technical barrier or license.

The paper is structured as follows. Section 2 introduces the model. In Section 3, the equilibria - prices, quantities and the number of firms - are derived for the three protective measures. Section 4 presents the resulting welfare rankings, and Section 5 concludes the paper. 


\section{The Model}

The starting point for the present model is Krugman's (1980) application of the Chamberlinian monopolistic competition approach - building on the contributions of Spence (1976) and Dixit and Stiglitz (1977) - to international trade.

It is assumed that the world consists of two symmetric countries with firms producing in the same industry. In both countries, market conditions are described by monopolistic competition, increasing returns to scale in production and differentiated goods. The industry has a large number of potential variants, which enter symmetrically into demand. Variants at home and abroad are different. Consumers want to consume both home and foreign variants.

The utility function of the model is based on Krugman (1981); it reinterprets the original version with a distinction into home and foreign products and applies the specific functional form from Krugman (1980) to both product groups. ${ }^{4}$ As the two countries are completely identical, it is sufficient to concentrate on the specification of the home country. Foreign variables are indicated by*. All individuals are assumed to have the same utility function,

$$
U=\ln \sum_{i=1}^{N_{H}} c_{H, i}^{\theta}+\ln \sum_{i=1}^{N_{M}} c_{M, i}^{\theta}
$$

where $0<\theta<1$ and $c_{M, i}$ is consumption of the $i$ th variant of imports and $C_{H, i}$ is consumption of the $i$ th variant of home products. In this setup, the imports $(M)$ of one country equal the exports $\left(Z^{*}\right)$ of the other country and vice versa. Furthermore, symmetry ensures that an implicit balanced trade assumption is employed. $N_{H}$ and $N_{M}$ define large numbers of potential variants of both home and foreign products. The number of variants actually produced, $n_{H}$ and $n_{M}$, are assumed to be large, although smaller than $N_{H}$ and $N_{M}$. On the supply side, it is assumed that there exists only one factor of production: labor. Firms can produce their specific variant for the home market, the foreign market, or both. When supplying the home or the foreign market, each firm produces with the same cost function:

$$
l_{j, i}=\frac{\alpha_{j}}{2}+\beta x_{j, i}
$$

where $j=H, Z$ and $l_{j, i}$ is labor used in the production of the $i$ th variant of the

\footnotetext{
${ }^{4}$ The specific functional form is also applied in Jørgensen and Schröder (2003 and 2005).
} 
home industry for servicing market $j, x_{j, i}$ is output of that variant for the respective market. Total labor in the production of the $i$ th variant is thus $l_{i}=l_{H, i}+l_{Z, i}$. This specification includes fixed costs, which are assumed to be some form of marketspecific access costs (marketing, advertising, distribution). For simplicity these are here assumed to be equal across countries, hence $\frac{\alpha_{j}}{2}=\frac{\alpha}{2}, j=H, Z$. Furthermore, $\beta$ is a constant marginal cost; hence average costs decline at a diminishing rate. Each variant is produced by only one firm, and each firm produces only one variant. Labor requirements (2) are converted into nominal costs by multiplying them by the wage rate, $w$.

The market clearing condition demands that the output of each variant should be equal to the total world consumption of that variant; more precisely that the markets for imports and home goods have to clear. Assuming full equality between the number of workers, $L$, and the number of consumers, this gives $x_{H, i}=L c_{H, i}$ and $x_{Z, i}=L^{*} c^{*}{ }_{M, i}$. Due to symmetry $L=L^{*}, x_{Z, i}=x_{M, i}{ }^{*}$ and $c^{*}{ }_{M, i}=c_{M, i}$. Also, labor market clearing demands $L=l_{i} n$ and $L^{*}=l_{i}^{*} * n^{*}$. Since each variant behaves identically, subscripts $i^{*}$ and $i$ are omitted in the remainder of the paper.

Finding equilibrium in this model follows the standard procedure; free entry and exit of firms, the zero-profit condition and labor and goods market clearing are assumed (see e.g. Krugman 1980). The firms' maximization can be separated for the two markets based on the profit functions $\prod_{j}=p_{j} x_{j}-\left(\frac{\alpha}{2}+\beta x_{j}\right) w$ where $j=H$, $Z$. The benchmark free trade equilibrium - with no technical barrier, import license or tariff - is characterized by prices $p$, output per firm $x$, and number of firms $n$.

$$
\begin{gathered}
p_{H}=p_{Z}=\frac{\beta w}{\theta} \\
x_{H}=x_{Z}=\frac{\theta \alpha}{2(1-\theta) \beta} \\
n_{H}=n_{z}=\frac{(1-\theta) L}{\alpha}
\end{gathered}
$$

Firms produce equal quantities for the home and for the foreign market and exported (thus also imported) and home goods have the same price. By symmetry we know that $x_{M}=x_{Z}$ and $n_{M}=n_{Z}$. The free trade benchmark in (3) to (5) also shows that each firm will want to produce its variant for both the home and the foreign market. 


\section{A. The measure of protection}

For subsequent comparison it is important to define the degree of protection generated by the three policy tools. We apply here a simple measure of protection, designed to capturing the idea that market access restrictions may both aim at limiting the total imports and/or at deterring foreign firms from accessing the domestic market. In particular, we define as our measure of protection,

$$
\phi=\frac{x_{M}^{P} n_{M}^{P}+\gamma\left(n_{M}^{P}-x_{M}^{P} n_{M}^{P}\right)}{x_{M} n_{M}+\gamma\left(n_{M}-x_{M} n_{M}\right)}
$$

where $0<\gamma \leq 1$ and $n_{M}^{P}$ and $x_{M}^{P} n_{M}^{P}$ are the number of foreign firms and the total import volume under some trade policy regime $P$, i.e. under technical barriers, licenses or a tariff. Thus $\phi=1$ represents free trade, while $\phi<\gamma$ implies a certain degree of protection. Furthermore, the parameter $\gamma$ allows us to distinguish the degree to which either the pure limitation of entry and existence of foreign firms on the domestic market is an issue $(\gamma=1)$ or the restriction of the total realized imports of all foreign firms is the objective of protection $(\gamma<1)$. Thus for any $\gamma<$ 1 the resulting level of protection $\phi$ can be achieved by either limiting the number of firms exporting or by reducing their individual export volumes or both. For our welfare comparisons of the three policy tools (section 4), the actual level of protection will then be held constant.

\section{Equilibrium with Market Access Barriers}

This section analyzes the effects of a technical barrier or standard, a license and a tariff on the market equilibrium. All measures will be applied bilaterally: in other words, we consider symmetric Nash equilibria. However, in principle even unilateral technical barriers or standards are captured by the exposition below, since what matters in such cases is that standards are different for the two markets. This will be true even if only one country creates a new domestic standard.

\section{A. Technical barriers and standards}

Following Maskus and Wilson (2001), a technical barrier or standard is modelled as an increase in fixed costs. Let $\sigma$ denote an additional additive market access costs that firms encounter when they want to supply the foreign market, i.e. when they have to employ staff to deal with a local regulation or adapt the design or 
specification of their product etc. The cost of the barrier is only encountered when exporting. Thus, the cost function for a firm that supplies the foreign market becomes

$$
\check{l}_{z}=\frac{\alpha_{Z}}{2}+\sigma+\beta \check{x}_{Z}
$$

where $\breve{l}_{z}$ is labor used for the production of exports of the variant, and $\check{x}_{\mathrm{z}}$ is the output of that variant for the export market under the presence of a technical barrier or standard.

The profit of a home firm, producing a variant and servicing both markets, is then given by $\check{\pi}=\check{p}_{H} \check{x}_{H}+\check{p}_{M}^{*} \check{x}_{z}-\left(\check{l}_{H}+\check{l}_{Z}\right) w$, where $\check{p}_{M}^{*}=\check{p}_{M}=\check{p}_{Z}$, i.e. consumer import prices (identical to the export prices) are identical in both countries and where $\breve{l}_{H}$ equals $l_{H}$ given in (2). The firm's problem can be split into two independent maximizations for the home and the foreign market respectively:

$$
\begin{aligned}
& \check{\pi}_{H}=\check{p}_{H} \check{x}_{H}-\left(\frac{\alpha}{2}+\beta \check{x}_{H}\right) w \\
& \check{\pi}_{Z}=\check{p}_{Z} \check{x}_{Z}-\left(\frac{\alpha}{2}+\sigma+\beta \check{x}_{H}\right) w
\end{aligned}
$$

Following the same procedures as above, the prices and quantities in each market and the resulting number of firms can be derived. The important characteristic of a technical barrier or standard is that labor is actually used in the process. Firms have to employ extra resources in order to circumvent the trade barrier. The workers employed in jobs associated with the technical barrier or standard still get wage $w$, and will demand both home and imported products hence, total spending power in the economy is unchanged. However, given a higher fixed cost of accessing the foreign market, not all firms will find it profitable actually to export their variant.

$$
\begin{aligned}
& \check{p}_{H}=\check{p}_{Z}=\frac{\beta w}{\theta} \\
& \check{x}_{H}=\frac{\alpha \theta}{2 \beta(1-\theta)}, \check{x}_{Z}=\frac{\alpha \theta}{2 \beta(1-\theta)} \frac{\alpha+2 \sigma}{\alpha} \\
& \check{n}_{H}=\frac{(1-\theta) L}{\alpha}, \quad \check{n}_{Z}=\frac{(1-\theta) L}{\alpha+2 \sigma}
\end{aligned}
$$

The number of firms are derived via the condition (stemming from the 
maximization of utility function (1)) that consumers will use equal shares of their income on imported goods and on home goods, i.e. $\check{p}_{j} \check{n}_{j} \check{x}_{j}=\frac{w L}{2}, j=H, Z$. Comparing the resulting equilibrium (8) - (10) with the free trade case (3)-(5) we see that the number of firms on the home market, the supply and price of home goods to the home market remain unchanged. Yet for exports, quantities have risen, while the number of firms (variants that are supplied) have fallen. This means that under the presence of a technical barrier not all firms find it worthwhile to export. ${ }^{5}$ Which variants will actually be exported remains indeterminant within the model. Thus, by symmetry, the technical barrier $\sigma$ succeeds in curtailing the market access of foreign firms to the domestic market.

So what is the resulting level of protection stemming from a technical barrier? Plugging the values for $x$ and $n$ from (9), (10), (4), and (5), into our measure of protection (6) we can express the level of protection $\bar{\phi}$, that results from some technical barrier to trade $\bar{\sigma}$ :

$$
\bar{\phi}=\frac{2 \alpha \beta \gamma(1-\theta)+\alpha(1-\gamma) \theta(\alpha+2 \bar{\sigma})}{2(\alpha+2 \bar{\sigma}) \beta \gamma(1-\theta)+\alpha(1-\gamma) \theta(\alpha+2 \bar{\sigma})}
$$

Notice, that in the special case where only the restriction of entry (the number) of foreign firms is an objective of protection $(\gamma=1)$ the protection level becomes $\frac{\alpha}{\alpha+2 \vec{\sigma}}$.

\section{B. Import license}

The license is different from a technical barrier, because - even though it enters the producer's problem as before - the license fee remains in the system. No real resources (labor) are used up when purchasing the license. It is assumed that all license revenues are redistributed to consumers. Consider an import license sold to foreign producers at price $S$. Purchase of the license entitles a firm to supply its variant to the market. How the license is allocated (by auction or sale), and how its price is determined is of no concern here; what matters is its effect on the firm's maximization. The profit function of a firm supplying both markets under the presence of a foreign licensing policy becomes $\hat{\pi}=\hat{p}_{H} \hat{x}_{H}+\hat{p}_{M}^{*} \hat{x}_{Z}-\left(\check{l}_{H}+\check{l}_{Z}\right) w-S$. The license fee in real terms is given by $s=\frac{S}{w}$, and the firm's profit function for the two markets can be restated as:

\footnotetext{
${ }^{5}$ This finding of a wedge between exporters and non-exporters as a result of a fixed cost in exporting was first established by Venables (1994). Yu (2002) utilizes this feature in his work on the role of entrepreneurship in foreign trade.
} 


$$
\begin{gathered}
\hat{\pi}_{H}=\hat{p}_{H} \hat{x}_{H}-\left(\frac{\alpha}{2}+\beta \hat{x}_{H}\right) w \\
\hat{\pi}_{z}=\hat{p}_{Z} \hat{x}_{Z}-\left(\frac{\alpha}{2}+s+\beta \hat{x}_{Z}\right) w
\end{gathered}
$$

From the firm's perspective, the situation under an import license is identical to the situation under a technical barrier to trade. Namely, the license expenditure enters the exporting firms' profit function as an increase in fixed costs. What has changed is that the license revenue is redistributed to the consumers. Again free entry and exit ensure that competition reduces industry profits to zero. The equilibrium is depicted by:

$$
\begin{gathered}
\hat{p}_{H}=\hat{p}_{Z}=\frac{\beta w}{\theta} \\
\hat{x}_{H}=\frac{\alpha \theta}{2(1-\theta) \beta} \quad \hat{x}_{Z}=\frac{\alpha \theta}{2(1-\theta) \beta} \frac{\alpha+2 s}{\alpha} \\
\hat{n}_{H}=\frac{(1-\theta) L}{\alpha+(1+\theta) s} \frac{\alpha+2 s}{\alpha}, \quad \hat{n}_{Z}=\frac{(1-\theta) L}{\alpha+(1+\theta) s}
\end{gathered}
$$

The number of firms can be calculated by utilizing the fact that half the income ${ }^{6}$ is spent on home goods and half on imports. The redistributed license fee is now included in household income, so that $\hat{p}_{Z} \hat{n}_{Z} \hat{x}_{Z}=\frac{w L^{*}+S \hat{n}_{\mu}^{*}}{2}$ must hold. Using the fact that $L=L^{*}$ and $\hat{n}_{Z}=\hat{n}_{M}^{*}$, one can calculate the number of firms that want to supply the foreign market and subsequently the number of firms that also want to supply the home market. As before, it turns out that not all firms will want to supply the foreign market. In comparison to the case of technical barriers and the free trade benchmark, the number of firms on the home market have increased, i.e. the license protection as opposed to a technical barrier has promoted the emergence of home firms, however, these are firms supplying the home market only.

To facilitate subsequent welfare comparisons it is useful to calculate the license fee $\bar{s}$ that limits the market access of foreign firms, such as to result in the same level of protection granted by a certain technical barrier $\bar{\sigma}$. Plugging $\hat{n}_{M}=\hat{n}_{Z}$ and $\hat{x}_{M}=\hat{x}_{Z}$ into (6) and equating to $\bar{\phi}$ given in (11) the corresponding import license must be:

\footnotetext{
${ }^{6}$ Including the income stemming from license revenues.
} 


$$
\bar{s}=\frac{4 \beta \gamma \bar{\sigma}}{2 \beta \gamma(1+\theta)-(1-\gamma) \theta(\alpha+2 \bar{\sigma})}
$$

For the special case of $\gamma=1$ the license becomes $\frac{2}{1+\theta} \bar{\sigma}$, thus illustrating that aiming at the same market protection the license fee has to be set higher than the cost of a technical barrier, because the redistribution of the license revenue stimulates some additional demand for foreign variants as well.

With the $\bar{s}$ given in (15), the concrete $\hat{x}_{Z}, \hat{n}_{Z}$ and $\hat{n}_{H}$ corresponding to a given market access restriction for foreign firms can be calculated.

\section{Tariff}

A tariff can limit the market penetration of foreign firms by distorting the foreign producers' revenue structure. Furthermore, under the implementation of tariffication or otherwise motivated reductions of existing technical or license trade barriers, a typical policy response is to replace the existing barrier by a tariff. Introducing tariffs into the model enables us to evaluate the welfare consequences of such a policy. Formally denoting variables under the presence of a tariff by, and using $t$ as the bilaterally imposed $a d$ valorem tariff we obtain the following prot functions for the two markets:

$$
\begin{gathered}
\tilde{\pi}_{H}=\tilde{p}_{H} \tilde{x}_{H}-\left(\frac{\alpha}{2}+\beta \tilde{x}_{H}\right) w \\
\tilde{\pi}_{Z}=(1-t) \tilde{p}_{Z} \tilde{x}_{Z}-\left(\frac{\alpha}{2}+\beta \tilde{x}_{Z}\right) w
\end{gathered}
$$

Applying the procedures of profit maximization, free entry and exit, and market clearing, the following equilibrium is derived.

$$
\begin{gathered}
\tilde{p}_{H}=\frac{\beta w}{\theta}, \quad \tilde{p}_{Z}=\frac{\beta w}{(1-t) \theta} \\
\tilde{x}_{H}=\frac{\alpha \theta}{2(1-\theta) \beta}, \quad \tilde{x}_{Z}=\frac{\alpha \theta}{2(1-\theta) \beta} \\
\tilde{n}_{H}=\frac{(1-\theta) L}{\alpha} \frac{2}{2-t}, \quad \tilde{n}_{Z}=\frac{(1-\theta) L}{\alpha} \frac{2-2 t}{2-t}
\end{gathered}
$$

The number of firms have to be calculated in two steps. The first is to establish the number of firms that wish to export via the condition $\tilde{p}_{Z} \tilde{n}_{Z} \tilde{x}_{z}=\frac{w L^{*}+t \tilde{p}_{M}^{*} \tilde{n}_{M}^{*} \tilde{x}_{M}^{*}}{2}$, using the 
fact that $L=L^{*}, \tilde{p}_{M}^{*}=\tilde{p}_{Z}, \tilde{x}_{M}^{*}=\tilde{x}_{Z}$ and $\tilde{n}_{M}^{*}=\tilde{n}_{Z}$. The second is to derive the number of firms which want to supply the home market from $\tilde{p}_{H} \tilde{n}_{H} \tilde{x}_{H}=\frac{w L+t \tilde{p}_{M} \tilde{n}_{M} \tilde{x}_{M}}{2}$, using the fact that $\tilde{n}_{M}$ equals the $\tilde{n}_{Z}$ (just derived above) and that $\tilde{x}_{M}=\tilde{x}_{Z}^{2}$. In line with other models with tariffs when industries are monopolistic competitive (see Gros (1987)), the tariff distorted equilibrium features a price increase for foreign goods and fewer foreign firms that supply the same volume each as under free trade. Thus again, not all home firms will export. What in fact has happened is that those firms that also export their variant have passed the tariff on to foreign consumers via the price increase, hence their per unit operating surplus remains unchanged. This means that their free trade output volume still results in them breaking even - free entry ensures that this applies to all exporting firms. However, as profits are extracted from the exporting activity, there is not as much room for firms, and hence fewer firms find it attractive to actually export. Thus $\tilde{n}_{Z}$ is below the free trade benchmark, while $\tilde{n}_{H}$ is above. The latter effect stems from the redistributed tariff revenue.

Finally the tariff level $\bar{t}$ that limits the number of foreign firms, $\tilde{n}_{M}$, and the import volume $\tilde{n}_{M} \tilde{x}_{M}$ to the level of protection given in (11), generated by a certain technical barrier $\bar{\sigma}$ can be calculated:

$$
\bar{t}=\frac{8 \beta \gamma(1-\theta) \bar{\sigma}}{8 \beta \gamma(1-\theta) \bar{\sigma}+\alpha(2 \beta \gamma(1-\theta)+(1-\gamma) \theta(\alpha+2 \bar{\sigma}))}
$$

With this $\bar{t}$, the concrete $\tilde{p}_{Z} \tilde{n}_{Z}$ and $\tilde{n}_{H}$ that emerge under a certain restriction on foreign firms can be calculated. For the simple case of $\gamma=1$ the value of $\bar{t}$ becomes $\frac{4 \sigma}{\alpha+4 \bar{\sigma}}$.

\section{Welfare Comparisons}

For our welfare comparison we distinguish two cases. Firstly, we examine the special case where protection only focuses on firm entry, i.e. the number of foreign firms that penetrate the domestic market. Secondly, we examine a more general case where the restriction of market access focuses on a measure of protection composed from both the number of foreign firms and total foreign imports. In the first case, where $\gamma=1$ and thus our measure of protection only takes into account the number of foreign firms active on the home market, we are able to derive clear analytical rankings of welfare under the three policy tools. For the second, and 
probably more realistic, case where the measure of protection also takes account of reductions in total import volumes $(\gamma<1)$ the resulting utility expressions do not allow for analytical solutions of rankings and we instead provide numerical simulations.

\section{A. Welfare when protection addresses entry $(\gamma=1)$}

Utility function (1) and the characterizations of equilibrium under free trade (3) (5), under a technical barrier (8) - (10) with a certain restriction $\bar{\sigma}$, under a license regime (12) -(14) with the license fee $\bar{s}=\frac{2}{1+\theta} \bar{\sigma}$ (from (15) after setting $\gamma=1$ ) and under a tariff regime (16) - (18) with the tariff $\bar{t}=\frac{4 \sigma}{\alpha+4 \bar{\sigma}}$ (from (19) after setting $\gamma=1)$ are used to calculate total consumer utility under the different policies.

$$
\begin{aligned}
& U=2 \ln \left(\frac{(1-\theta) L}{\alpha}\left(\frac{\alpha \theta}{2(1-\theta) \beta}\right)^{\theta}\right) \\
& \check{U}=U+\ln \left(\frac{\alpha}{\alpha+2 \bar{\sigma}}\left(\frac{\alpha+2 \bar{\sigma}}{\alpha}\right)^{\theta}\right) \\
& \hat{U}=U+\ln \frac{\alpha}{\alpha+2 \bar{\sigma}} \frac{\alpha+\theta \alpha+4 \bar{\sigma}}{(1+\theta)(\alpha+2 \bar{\sigma})}\left(\frac{\alpha(1+\theta)+4 \bar{\sigma}}{\alpha(1+\theta)}\right) \\
& \tilde{U}=U+\ln \left(\frac{\alpha}{\alpha+2 \bar{\sigma}} \frac{\alpha+4 \bar{\sigma}}{\alpha+2 \bar{\sigma}}\right)
\end{aligned}
$$

Figure 1 shows these utility levels for the three policies, with the effective protection stemming from a certain $\bar{\phi}$ expressed as $\bar{n}_{M}=\frac{(1-\theta) L}{\alpha+2 \bar{\sigma}}$ on the x-axis.

Figure 1. Utility with a limited number of foreign firms $(\gamma=1)$

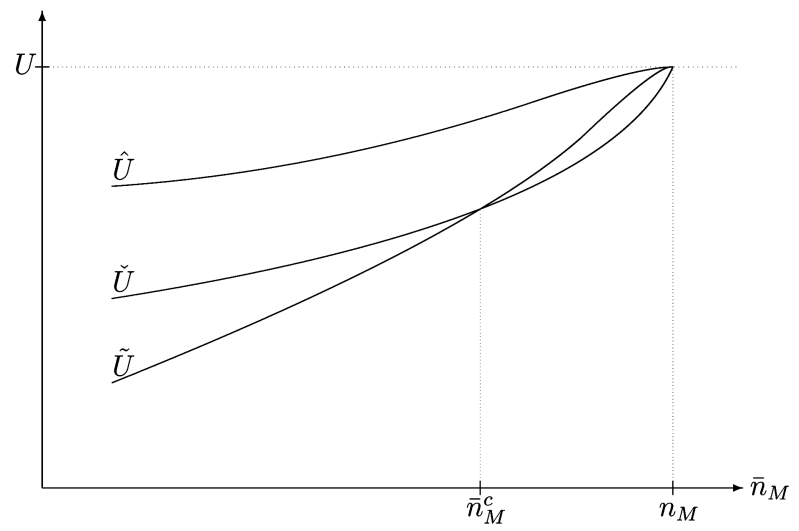


Without protection $\phi=1$ (thus $\bar{\sigma}=\bar{s}=\bar{t}=0$ ) we have the free trade number of firms, $n_{M}$, and all three regimes start in the utility level of the free trade benchmark. Then, moving to the left, protection increases as the market entry of foreign firms is gradually restricted. The locus of the technical barrier $(\check{U})$ crosses the $\operatorname{tariff}(\tilde{U})$ at some value $\bar{n}_{M}^{c}$, while the utility under a license $(\hat{U})$ even though below the free trade level is always above the two other policies for the entire range of limited market access. These patterns are established formally in the following results.

First of all it can be shown that $U>\check{U}, \hat{U}, \tilde{U}$ i.e. free trade utility is larger than utility under the presence of a technical barrier, an import license or a tariff (see appendix A.1). Furthermore, since the derivatives of (21), (22) and (23) with respect to $\bar{\sigma}$ are negative, i.e. $\check{U}^{\prime}, \hat{U}^{\prime}, \tilde{U}^{\prime}<0$, a first immediate result concerns the abolishment of trade barriers and the harmonization of technical standards:

Result 1. Given that $\gamma=1$, reductions in technical barriers, the harmonizations of standards, the abolishment of import licensing and the liberalization of tariffs are all welfare improving policies.

More important - and less obvious - the welfare rankings between the different policies can be derived. Since $\check{x}_{H}=\hat{x}_{H}$ and by definition $\check{n}_{Z}=\hat{n}_{Z}=\bar{n}_{M}$ but $\check{n}_{H}<\hat{n}_{H}$ and $\check{x}_{Z}<\hat{x}_{Z}$ the following result can be stated:

Result 2. Given that $\gamma=1$ and given a certain restriction, $\bar{n}_{M}$, on the number of foreign firms that access the domestic market, protection with an import license is always preferable to protection with a technical barrier or standard, in particular

$$
\hat{U}(\bar{s})>\check{U}(\bar{\sigma})
$$

The utility under the license regime (22) is larger than the utility under a technical barrier to trade (21). Thus keeping the number of foreign firms on the domestic market constant, utility is improved, as technical barriers or standards are replaced by license arrangements. The intuition behind this ranking is as follows: technical barriers to trade or standards burn up resources (resources which give no utility). An import license on the other hand, does also succeed in reducing the number of foreign firms. However, since no resources are actually used, but merely redistributed, it allows for a larger - compared to a technical barrier - total production volume (and hence also consumption). 
Comparing a tariff restriction to an import license one attains the some-what surprising insight that a licensing scheme is associated with higher welfare than a tariff-driven market entry barrier. Formally:

Result 3. Given that $\gamma=1$ and given a certain restriction, $\bar{n}_{M}$, on the number of foreign firms that access the domestic market, protection with an import license is always preferable to protection with a tariff, in particular

$$
\hat{U}(\bar{s})>\tilde{U}(\bar{t})
$$

For proof see appendix (A.2). The utility under the license regime (22) is larger than the utility under a tariff barrier (23); result 3 holds for all levels of protection, given that protection follows the assumption of only addressing market entry, i.e. that we are in the $\gamma=1$ case, in section $\beta$ below we will see how this result alters once $\gamma<1$.

Comparing utility under a tariff (23) with utility under a technical barrier (21), it can be established that the utility ranking switches within the possible range of market access limitation. The following result can be stated:

Result 4. Given that $\gamma=1$, there exists a unique protection level, $\bar{n}_{M}^{c}>0$ obtained by a corresponding unique technical barrier $\bar{\sigma}^{c}>0$ and tariff level $\bar{t}^{c}=\frac{4 \bar{\sigma}}{\alpha+4 \bar{\sigma}}>0$ respectively, such that

(a) utility under a technical barrier is lower than utility under the tariff for lower levels of protection, namely $\left.\check{U}\right|_{\bar{n}_{M}>\bar{n}_{M}^{c}}<\left.\tilde{U}\right|_{\bar{n}_{M}>\bar{n}_{M}^{c}}$, and

(b) utility under a technical barrier is higher than utility under the tariff for higher levels of protection, namely $\left.\check{U}\right|_{\bar{n}_{M}<\bar{n}_{M}^{c}}>\left.\tilde{U}\right|_{\bar{n}_{M}<\bar{n}_{M}^{c}}$.

Proof of the result is given in appendix A.3. Thus, from a welfare point of view, limiting the market entry of foreign firms, using a tariff instead of a technical barrier, is preferable for moderate levels of protection, while for high levels of protection (in the sense of $\bar{n}_{M}^{c}$ ) a technical barrier is preferable to a tariff regime, even though all tariff revenues are completely redistributed. The result is driven by the following mechanism: under a technical barrier, the number of foreign firms are simply reduced (while each firm that decides to export does increase its 
individual export volume), resulting in less utility stemming from imported goods (as there is love of variety) while the home market remains unaffected. Under a tariff, two opposing forces are at work. First, via the redistributed tariff revenue, consumers are partially compensated for the restriction of imports by being able to spend more funds on home goods. Second, the tariff actually reduces not only the number of foreign firms but also the export volume of each firm, and thus the total import volume. Result 4 is driven by the following intuition: for high levels of protection, the ability of the tariff actually to reduce the total import volume, $\tilde{n}_{M} \tilde{x}_{M}$, cuts severely into consumer utility. For low levels of protection, however, even so the total import volume is still smaller under the tariff than with a technical barrier, the redistribution of tariff revenues - and thus increased consumption of home goods compensates consumers enough to achieve a higher utility than under the technical barrier.

\section{B. Welfare when protection addresses import volume and entry $(\gamma<1)$}

We are now able to turn to the more complex case, namely when protection, i.e. limiting market access of foreign firms, not only concerns entry but also import volumes, i.e dealing with cases of $\gamma<1$. Using utility function (1) and the characterizations of equilibrium under the three policy tools, and the values for the license fee $\bar{s}$ in (15) and the tariff $\bar{t}$ from (19) one can calculate utility expressions that each commands exactly the same level of protection $\bar{\phi}$ as generated by a certain technical barrier $\bar{\sigma} .^{7}$ Obviously utility under free trade and utility under the technical barriers are still given by (20) and (21) respectively, while utility under the license and the tariff regime now both depend on $\bar{\sigma}$ and $\gamma$ (see appendix A.4). The resulting utility expressions do not lend themselves to analytical comparison, and we have to rely on numerical simulations instead. Figure 2 plots various examples of the resulting utility. For these examples we have set $\alpha=2, \beta=1$ and $L=100 .^{8}$ In each of the 9 panels $\bar{\sigma}$ runs from 0 to 3 , thus representing increasing protection levels. ${ }^{9}$ From the left to the right, panels in Figure 2 show lower levels

\footnotetext{
${ }^{7}$ We conduct the subsequent comparisons with respect to $\bar{\sigma}$ since by (11) each $\bar{\sigma}$ is associated with a unique protection level $\bar{\phi}$.

${ }^{8}$ The measures on the horizontal axis in figure 1 and 2 are not identical. In figure 2 the measure is $\bar{\sigma}$ because the focus is both on import volume and entry and not only on entry as in figure 1 .

${ }^{9}$ We take 3 as an upper limit since we view feasible technical barrier to be in the order of the fixed costs $\alpha=2$.
} 
Figure 2. Utility with market access restriction $(\gamma<1)$
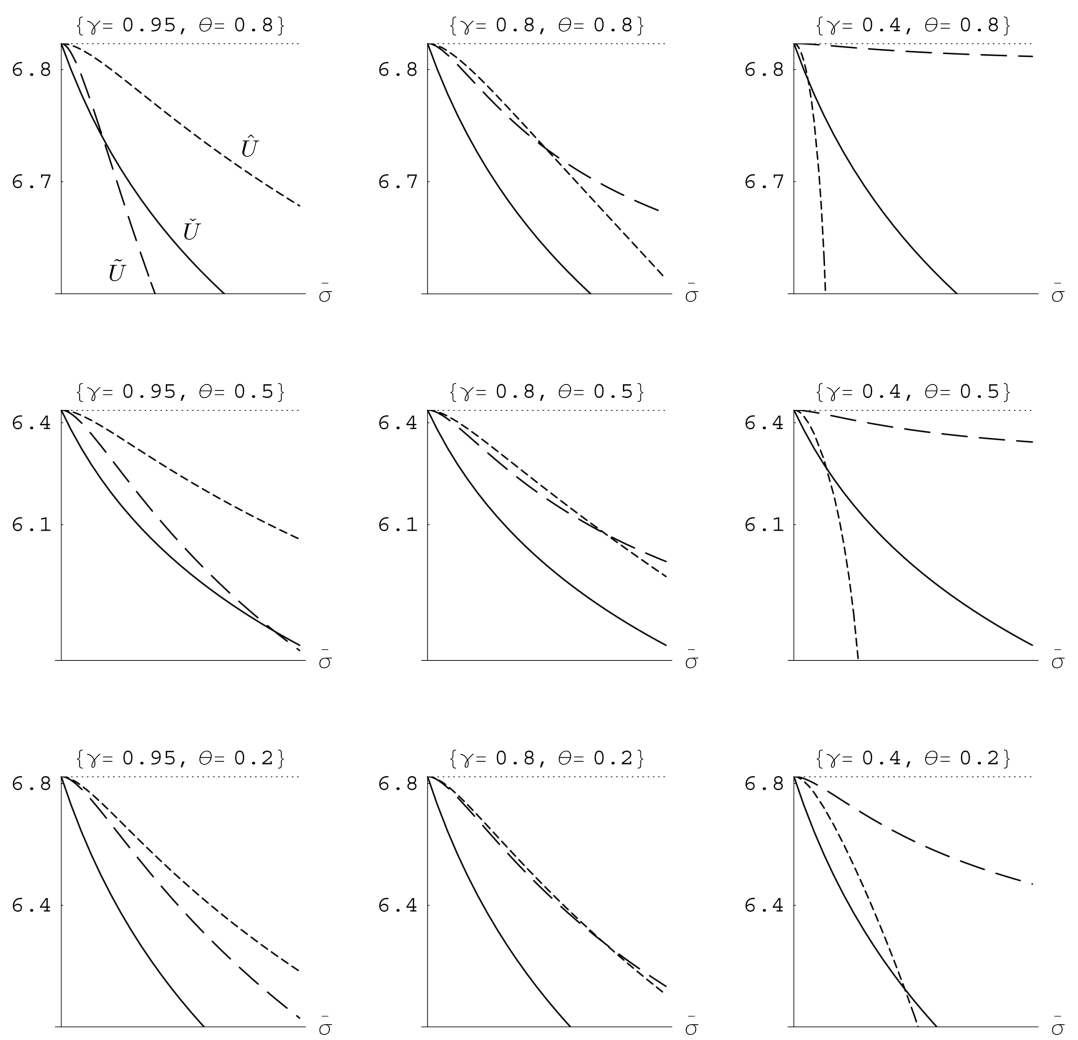

of $\gamma$, i.e. an increasing focus on protection from total import volumes. From the top to the bottom panels in Figure 2 show lower levels of $\theta$, i.e. a stronger consumer preference for variety. Utility under a technical barrier is plotted with a solid curve, the curve with short dashes plots utility under the license and utility under a tariff is plotted with long dashes. The horizontal dotted line in each panel shows the free trade utility level.

As expected the first column of panels $(\gamma=0.95)$ displays the same qualitative results as the analytical solution of the section $\mathrm{A}$ and thus mirrors Figure 1 with an inverted first axis. For this high level of $\gamma$, i.e. paying predominantly attention to entry restriction, the license barrier is welfare superior, and the technical barrier dominates the tariff for high level of protection. ${ }^{10}$ However, the second and third columns of panels in Figure 2 illustrate, that the performance of the license regime

${ }^{10}$ In the bottom left panel the intersection of $\tilde{U}$ and $U$ occurs for $\bar{\sigma}>3$ hence is not within the plot range. 
quickly deteriorates as more focus is placed on restricting import volumes. Quickly the tariff turns out to become the welfare superior tool for protection. In contrast, the license loses and eventually (third column) is even dominated by the technical barrier for high levels of protection. ${ }^{11}$

These patterns are stated formally in the following results.

First of all since all plots in figure 2 display negative slopes we can confirm result 1 :

Result 5. Given that $\gamma<1$, reductions in technical barriers, the harmonizations of standards, the abolishment of import licensing and the liberalization of tariffs are all welfare improving policies.

Furthermore, concerning the effect of widening the protection objective towards addressing total import volume, i.e. going beyond the simple focus on the pure number of foreign entries on the home markets we find:

Result 6. There exists some critical $\mathcal{\gamma}<1$, such that for a suciently strong emphasis on total import volume in the protection measure, in the sense of $\gamma<\gamma$ the tariff is the welfare dominant tool for all levels of protection. In particular

$$
\tilde{U}(\bar{t})>\hat{U}(\bar{s}), \check{U}(\bar{\sigma}) \forall \gamma \in\left[0, \gamma^{c}\right]
$$

The driver of result 6 , is of course that the role of limiting total import volumes becomes sufficiently important for $\gamma<\gamma^{c}$, and since only the tariff manages to reduces both the number of firms entering the home market and their individual export volumes, it dominates in terms of welfare both the license regime and the technical barrier.

In particular, result 6 contrasts result 3 which was derived under the stark assumption of only addressing market entry, i.e. in the $\gamma=1$ case. Once only the restriction of the number of firms importing to the domestic market is the objective, then, utility is lost, as a licensing regime is replaced by a tariff arrangement. However, by result 6 we find that, for a sufficient focus on restricting total import volumes, the inverse is true. The intuition behind this ranking of the two policies is

\footnotetext{
${ }^{11}$ Variation with respect to $\theta$ shows that the more consumers love variety (i.e. $\theta$ is small), the bigger is the impact on utility of restricting market access. The reason is, that restricting market access reduces the number of importing firms and hence, the number of variants of imports available. The policy of technical barriers performs relatively worse when $\theta$ is falling compared to the other kinds of policies.
} 
as follows: both policies, the license and the tariff, redistribute the revenues that are harvested from foreign producers, so in this respect, the two methods are identical and the total spending power within the economy is maintained - in contrast to the situation with a technical barrier to trade. However, only the tariff - in contrast to the license (and in fact the technical barrier) - does in fact reduce the total $\left(\tilde{n}_{M} \tilde{x}_{M}\right)$ as well as the market access of foreign firms. This is exactly what causes the superior performance of the tariff in result 6 , i.e. once protection is also concerned with total import volume $(\gamma<1)$. What is happening is that the tariff, a tax on foreign producers, forces firms to raise prices, and thus reduces their sales. The results are opposite in the case of a license: the increased fixed costs induce firms to increase their output volume, so as to be able to recover their increased market access costs. With increased output volume per firm, there is room for fewer firms (less entry). Thus while the number of firms are reduced, the total import volume $\left(\tilde{n}_{M} \tilde{x}_{M}\right)$ stays constant, resulting in higher utility compared to the tariff. Finally, results 7 and 8 address the situations where the dominance of a policy tool depends on the level of protection aimed at.

Result 7. For all $\gamma<\mathcal{\gamma}$ there exists some critical level of protection $\bar{\phi}^{d}$ such that

(a) utility under a license barrier is higher than utility under the technical barrier for lower levels of protection, namely $\left.\hat{U}\right|_{\phi>\bar{\phi}^{d}}>\left.\check{U}\right|_{\phi>\bar{\phi}^{d}}$,

(b) utility under a license barrier is lower than utility under the technical barrier for high levels of protection, namely $\left.\hat{U}\right|_{\phi<\bar{\phi}^{d}}<\left.\check{U}\right|_{\phi<\bar{\phi}^{d}}$.

This result relates to the intersection of the utility levels under a license and utility under a technical barrier displayed in the last column of figure 2, where $\bar{\sigma}$ maps uniquely onto $\bar{\phi}^{d}$. Finally, we have results concerning the performance of the import license in relation to a tariff barriers:

Result 8. There exists some critical $\gamma^{d}>\mathcal{\gamma}$, such that for all $\gamma \in\left[\mathcal{\gamma}, \gamma^{d}\right]$ there exists a level of protection $\phi^{e}$ such that

(a) utility under a license barrier is higher than utility under the tariff for lower levels of protection, namely $\left.\hat{U}\right|_{\phi>\phi^{e}}>\left.\tilde{U}\right|_{\phi>\phi^{e}}$,

(b) utility under a license barrier is lower than utility under the tariff for high levels of protection, namely $\left.\hat{U}\right|_{\phi<\phi^{e}}>\left.\tilde{U}\right|_{\phi<\phi^{e}}$.

This result relates to the middle column of figure 2 with $\phi^{e}$ corresponding to a 
unique $\bar{\sigma}$.

The central message of the above results is that tariffs, even though they may be inefficient if only the limitation of entry by foreign firms is the objective of protection policies, clearly outperform technical barriers and import licensing schemes once import volumes play a suciently important role in protectionist policies. We take it, that this latter condition is fulfilled by the protective stances of most real world policy makers. A surprising insight remains, however: technical barriers may, when the restriction of foreign entry (import volume) is an important objective, outper-form tariffs (licensees) if high levels of protection are to be maintained; yet, in this situation technical barriers are in turn dominated by licenses (tariffs). These results occur even though the technical barrier has no direct impact on consumer welfare, but constitutes a pure waste of resources, while both the license and the tariff revenue are fully redistributed.

\section{Conclusion}

The paper employs a simple two-country monopolistic competition model of international trade to study the welfare impact of technical barriers to trade, standards, import licenses and tariffs, policies that have been and still often are being (ab)used as means of limiting the market access of foreign firms. It deals with the welfare impact of such policies and what is more important, with the expected effects of replacing one type of policy by another. The paper introduces a measure of protection that captures the idea that market access restrictions may both aim at limiting total import volume and/or reduce the number of foreign firms on the domestic market. In the special case where protection only focuses on firm entry, it is found analytically that - contrary to what one might expect - a technical barrier to trade can in fact command the higher total consumer welfare than a corresponding tariff, where both measures have imposed the same limit on the number of foreign firms that enter the domestic market. This case occurs for high levels of protection, i.e. a severe limitation on market access. For low levels of protection, i.e. a moderate limitation on market access, the tariff will be the better

policy tool. In any case, the superior policy tool across the entire range of market access limitation is the direct tool of controlling market access via import licenses. Such a policy commands the highest consumer welfare.

In the complex situation where the protection measure takes account of the total import volume the rankings change. The paper shows that for sufficient emphasis 
on import volume in the protection measure the tariff tool becomes the welfare dominant tool for all levels of protection. Furthermore, it is found that there exists a critical level of protection such that the license scheme dominates technical barriers for low levels of protection whereas technical barriers dominate a license scheme for high level of protection.

The intuition behind the welfare rankings found in this paper for the three policy tools relies on the nature of the costs imposed upon the foreign producer. While both a license and a tariff redistribute the costs imposed on foreign producers to the domestic consumers, the technical barrier (or standard) burns up resources, such that a license and tariff should in principle create the higher welfare. The important difference between the three tools, and the reason why the tariff performs badly under the simple measure of protection but dominates the other tools for the more complex measure of protection, is that although all the different measures limit the number of foreign firms, only the tariff succeeds in actually reducing the trade volume, since foreign firms react to it by increasing prices, resulting in lower sales. On the other hand, under a technical barrier or import license, those foreign firms that decide to enter the domestic market will in fact increase their export volume so as to be able to recover the increase in fixed costs caused by the technical barrier or license.

These welfare rankings have potentially policy implications for the efforts of the Uruguay Round to replace non-tariff barriers with corresponding tariffs. Overall, all three policy tools do reduce welfare - so this paper does not provide a rationale for the imposition of devices limiting market access. On the contrary, it shows that reductions in technical barriers and tariffs, the removal of licensing schemes, and a harmonization of standards are all welfare improving policies.

Received 6 April 2004, Accepted 18 January 2005

\section{Acknowledgement}

This paper beneted substantially of comments from an anonymous referee and from the comments of Paul Gregory, Roy Run and Harald Trabold. The authors alone are responsible for any remaining errors. 


\section{References}

Bhagwati, J. (1988), Protectionism, Cambridge (Mass.): MIT Press.

Baldwin, R.E. (1984), Trade Policies in Developed Countries, in R. Jones and P. Kenen (eds), Handbook of International Economics, Vol. 1, Amsterdam: North Holland.

Brenton, P. and Manzocchi, S. (eds.) (2002), Enlargement, Trade and Investment - The Impact of Barriers to Trade in Europe, Edward Elgar.

Brenton, P., Sheehy, J. and Vencauteren M. (2001), Technical Barriers to Trade in the European Union: Importance for Accession Countries, Journal of Common Market Studies, 39(2), 265-84.

Casella, A. (1997), Product Standards Coalitions in a Market without Borders, CEPR Discussion paper, No. 1584.

Chen, N. (2004), Intra-national versus international trade in the European Union: why do national borders matter?, Journal of International Economics, 63, 93-118.

Dixit, A.K. and J.E. Stiglitz (1977), Monopolistic Competition and Optimum Product Diversity, American Economic Review, 67(3) 297-308.

EU-Commission (1998), Technical barriers to trade, Vol. 1, Subseries III: Dismantling of Barriers, The Single Market Review.

Fujita, M.; Krugman, P. and Venables, A.J. (1999), The Spatial Economy: Cities, regions, and international trade, Cambridge, MA, MIT Press.

Ganslandt, M. and Markusen, J.R. (2001), Standards and Related Regulations in International Trade: A Modeling Approach, in Maskus, K.E. and Wilson, J.S (eds.), Quantifying the Impact of Technical Barriers to Trade: Can It Be Done?, The University of Michigan Press.

Gervais, J.-P. and Surprenant, D. (2000), An Economic Investigation of the Import Licensing Methods and TRQs in Agriculture, Canadian Journal of Agricultural Economics, Vol. 48, No. 4, pp.397-410.

Gros, D. (1987), Protectionism in a Framework with Intra-industry Trade: tariffs, Quotas, Retaliation, and Welfare Losses. International Monetary Fund Papers, Vol. 34 (1), 86-114.

Helpman E. and Krugman P. (1989), Trade Policy and Market Structure, Cambridge, MA, MIT Press.

Krishna, K. (1993), Theoretical Implications of Imperfect Competition on Quota License Prices and Auctions, World Bank Economic Review, 7, 13-136.

$\mathrm{J} \varnothing$ orgensen, J.G, and P.J.H. Schröder (2003). Reductions in Real versus Tariff Barriers: The Impact on Industry Concentration. Journal of Industry, Competition and Trade, Vol. 3 (4), pp. 251-268.

J $\varnothing$ orgensen, J.G, and P.J.H. Schröder (2005). Welfare Ranking Ad Valorem and Specific Tariffs under Monopolistic Competition. Canadian Journal of Economics, forthcoming.

Ker, A.P. (2000), Modeling Technical Trade Barriers Under Uncertainty, Journal of Agri- 
cultural and Resource Economics, 25(1), 28-50.

Krugman, P. (1980), Scale Economies, Product Dierentiation, and the Pattern of Trade, American Economic Review, 70(5), 950-959.

Krugman, P. (1981), Intraindustry Specialisation and the Gains from Trade, Journal of Political Economy, 89(5), 959-973.

Maskus, K.E. and Wilson, J.S (eds.)(2001), Quantifying the Impact of Technical Barriers to Trade: Can It Be Done?, The University of Michigan Press.

Maskus, K.E., Otsuki, T. and Wilson, J.S., (2001), An Empirical Framework for Analyzing Technical Regulations and Trade, in Maskus, K.E. and Wilson, J.S (eds.), Quantifying the Impact of Technical Barriers to Trade: Can It Be Done?, The University of Michigan Press.

Roberts, D. and DeRemer, K. (1997), An overview of foreign technical barriers to U.S. agricultural exports, Staff Paper AGES-no.9705, Economic Research Service, U.S. Department of Agriculture.

Skully, D.W. (1999), The Economics of TRQ Administration, Working Paper no. 99-6, International Trade Research Consortium.

Spence, M. (1976), Product Selection, Fixed Costs and Monopolistic Competition, Review of Economic Studies, 217-235.

Venables, A.J. (1987), Trade and Trade Policy with Differentiated Products: A Chamberlinian-Ricardian Model, The Economic Journal, Vol. 97, pp.700-717.

Venables, A.J. (1994), Integration and the export behavior of firms: trade costs, trade volumes and welfare, Weltwirtschaftliches Archiv, 130(2), 118-132.

Weyerbrock, S. and Xia, T. (2000), Technical Trade Barriers in US/Europe Agricultural Trade, Agribusiness, 16(2), pp. 235-251.

Yu, Zhihao (2002), Entrepreneurship and Intra-Industry Trade, Weltwirtschaftliches Archiv, 138(2), 277-290. 


\section{Appendix}

\section{A.1 Free trade utility versus utility with limited market access}

Proof. Proof that $U>\check{U}, \hat{U}, \tilde{U}$. Utility under trade protection is less than utility under free trade.

A.1.1 Proof that $U>\check{U}$

From (21) it follows that $\check{U}=U+\ln \left(\frac{\alpha}{\alpha+2 \bar{\sigma}}\left(\frac{\alpha+2 \bar{\sigma}}{\alpha}\right)^{g}\right)$. Hence, one has to show that:

$$
\check{K}=\frac{\alpha}{\alpha+2 \bar{\sigma}}\left(\frac{\alpha+2 \bar{\sigma}}{\alpha}\right)^{\theta}<1
$$

It follows from (A.1) that $\lim _{\sigma \rightarrow 0} \check{K}=1$. Since

$$
\frac{\partial \check{K}}{\partial \sigma}=\frac{2 \alpha(\theta-1)\left(1+\frac{2 \sigma}{\alpha}\right)^{\theta}}{(\alpha+2 \bar{\sigma})^{2}}<0
$$

$\check{K}$ is monotonically decreasing in $\sigma, \forall \sigma>0$, and thus (A.1) is fullled.

\section{A.1.2 Proof that $U>\hat{U}$}

From (22) it follows that $\hat{U}=U+\ln \left(\frac{\alpha}{\alpha+2 \bar{\sigma}} \frac{\alpha+\theta \alpha+4 \bar{\sigma}}{(1+\theta)(\alpha+2 \bar{\sigma})}\left(\frac{1(1+\theta)+4 \bar{\sigma}}{\alpha(1+\theta)}\right)\right)$. Hence, one has to show that:

$$
\hat{K}=\frac{\alpha}{\alpha+2 \sigma} \frac{\alpha+\theta \alpha+4 \sigma}{(1+\theta)(\alpha+2 \sigma)}\left(\frac{\alpha(1+\theta)+4 \sigma}{\alpha(1+\theta)}\right)^{\theta}<1
$$

It follows from (A.3) that $\lim _{\sigma \rightarrow 0} \hat{K}=1$. Since

$$
\frac{\partial \hat{K}}{\partial \sigma}=\frac{8 \alpha(\theta-1) \sigma\left(\frac{\alpha+\theta \alpha+4 \sigma}{\alpha+\alpha \theta}\right)^{\theta}}{(1+\theta)(\alpha+2 \sigma)^{3}}<0
$$

$\hat{K}$ is monotonically decreasing in $\sigma, \forall \sigma>0$, and thus (A.3) is fulled.

A.1.3 Proof that $U>\tilde{U}$ 
From (23) it follows that $\tilde{U}=U+\ln \left(\frac{\alpha}{\alpha+2 \bar{\sigma}} \frac{\alpha+4 \bar{\sigma}}{\alpha+2 \bar{\sigma}}\right)$. Hence, one has to show

$$
\tilde{K}=\frac{\alpha}{\alpha+2 \bar{\sigma}} \frac{\alpha+4 \bar{\sigma}}{\alpha+2 \bar{\sigma}}<1
$$

which is true $\forall \sigma>0$.

\section{A.2 Proof of result 3}

Proof. Proof that $\hat{U}(\bar{s})>\tilde{U}(\bar{t})$

From (22) and (23) it follows that:

$$
\hat{U}-\tilde{U}=\ln \left(\frac{\alpha+\theta \alpha+4 \sigma}{(1+\theta)(\alpha+2 \sigma)}\left(\frac{\alpha(1+\theta)+4 \sigma}{\alpha(1+\theta)}\right)^{g}\right)-\ln \left(\frac{\alpha+4 \sigma}{\alpha(1+\theta)}\right)
$$

Hence, one has to show that:

$$
\ln \left(\frac{\alpha+\theta \alpha+4 \sigma}{(1+\theta)(\alpha+2 \sigma)}\left(\frac{\alpha(1+\theta)+4 \sigma}{\alpha(1+\theta)}\right)^{q}\right) \geq \ln \left(\frac{\alpha+4 \sigma}{\alpha+2 \sigma}\right) \forall \sigma \geq 0
$$

From (A.7) it follows that one has to show that:

$$
D=-\alpha-4 \sigma+\alpha\left(\frac{\alpha+\theta \alpha+4 \sigma}{\alpha+\alpha \theta}\right)^{1+\theta} \geq 0
$$

From A.8 we have that $\lim _{\sigma \rightarrow 0} D=0$. Since

$$
\frac{\partial D}{\partial \sigma}=4\left(-1+\left(1+\frac{4 \sigma}{\alpha+\alpha \sigma}\right)^{q}>0\right.
$$

$\mathrm{D}$ is monotonically increasing in $\sigma, \forall \sigma>0$, and thus (A.7) is fullled.

\section{A.3 Proof of result 4}

Proof. Proof that there exists a unique protection level $\bar{n}_{M}^{C}>0$ (corresponding to a unique technical barrier $\bar{\sigma}^{c}>0$ and tariff $\bar{t}^{c}>0$ such that:

$$
\left.\check{U}\right|_{\bar{n}_{M}^{c}}=\left.\tilde{U}\right|_{\bar{n}_{M}^{c}}
$$

From (21) and (23) it follows that (A.10) implies that:

$$
\left(\frac{\alpha+2 \sigma}{\alpha}\right)^{\theta}=\frac{\alpha+4 \sigma}{\alpha+2 \sigma}
$$

An analytical solution to (A.11) cannot be expected due to the fact that the left- 
hand side is taken in power $\theta$. However, it can be shown that there exists a unique positive solution to (A.11), i.e. $\bar{\sigma}^{c}>0$ (and hence a corresponding and unique $\bar{n}_{M}^{c}>0$ and $\left.\tilde{t}^{c}>0\right)$.

Define $\rho=\frac{2 \sigma}{\alpha}$ and (A.11) becomes:

$$
(1+\rho)^{\theta+1}=1+2 \rho
$$

Define next $v=1+\rho$ and (A.12) becomes

$$
v^{\theta+1}=2 v-1
$$

Next dene the two functions $\phi(v)=2 v-1$ and $\varphi(v)=v^{\theta+1} . \phi(v)$ and $\varphi(v)$ cut twice at $v=1$ and at $\bar{v}>1$. For small $v$ (i.e. $v<1), \phi(v)<\varphi(v)$ and again for large $v$ (i.e. $v>\bar{v}$ ) we have $\phi(v)<\varphi(v)$ as $v$ is lifted in a higher power in $\varphi(v)$ than in $\phi(v)$. For $1<v<\bar{v}$ we have $\phi(v)>\varphi(v)$. By backward substitution we have:

$$
\begin{gathered}
v=1 \Rightarrow \rho=0 \Rightarrow \sigma=0 \\
v=\bar{v}>1 \Rightarrow \rho>0 \Rightarrow \sigma>0
\end{gathered}
$$

Hence, (A.14) shows that $\check{U}=\tilde{U}$ with free trade (i.e. with $n_{M}$ ), whereas (A.15) gives $\bar{\sigma}^{c}$ (and thus also $\bar{n}_{M}^{c}$ and $\bar{t}^{c}$ ) where $\check{U}=\tilde{U}$. For $0<\sigma<\bar{\sigma}^{c}$ (i.e. $\left.\bar{n}_{M}^{c}<\bar{n}_{M}<n_{M}\right)$ we have $\tilde{U}>\check{U}$ and for $\sigma>\bar{\sigma}^{c}$ (i.e. $\bar{n}_{M}<\bar{n}_{M}^{c}$ ) we have $\check{U}>\tilde{U}$.

\section{A.4 Utility expressions for $\hat{U}$ and $\tilde{U}$ when $\gamma<1$}

$$
\begin{aligned}
\hat{U}= & \ln \left(\frac{L(1-\theta)^{(1-\theta)}(\alpha \theta)^{\theta}(2 \beta)^{-\theta}(8 \beta \gamma \sigma+\alpha(2(\beta \gamma(1+\theta)-(1-\gamma) \theta \sigma)-\alpha(1-\gamma) \theta))}{\alpha(2 \beta \gamma(1+\theta)-\alpha(1-\gamma) \theta)(\alpha+2 \sigma)}\right) \\
& +\ln \left(\frac{L(1-\theta)\left(\frac{\theta\left(\alpha+\frac{8 \beta \gamma \sigma}{2 \beta \gamma(1+\theta)-(1-\gamma) \theta(\alpha+2 \sigma)}\right)}{\beta-\beta \theta}\right)^{\theta}}{2^{\theta}\left(\alpha+\frac{4 \beta \gamma(1+\theta) \sigma}{2 \beta \gamma(1+\theta)-(1-\gamma) \theta(\alpha+2 \sigma)}\right)}\right)
\end{aligned}
$$




$$
\begin{aligned}
& \tilde{U}=\ln \left(\left(\frac{L(1-\theta)^{(1-\theta)}(\alpha \theta)^{\theta}(2 \beta)^{-\theta}(2 \beta \gamma(1-\theta)+(1-\gamma) \theta(\alpha+2 \sigma))}{(2 \beta \gamma(1-\theta)+\alpha(1-\gamma) \theta)(\alpha+2 \sigma)}\right)\right) \\
& +\ln \left(\frac{2^{1-\theta} L(1-\theta)^{(1-\theta)}(\alpha \theta)^{\theta} \beta^{-\theta}}{\alpha\left(2-\frac{8 \beta \gamma(1-\theta) \sigma}{\alpha^{2}(1-\gamma) \theta+8 \beta \gamma(1-\theta) \sigma+2 \alpha(\beta \gamma(1-\theta)+(1-\gamma) \theta \sigma)}\right)}\right)
\end{aligned}
$$

